Article

\title{
Effect of Moist Cooking Blanching on Colour, Phenolic Metabolites and Glucosinolate Content in Chinese Cabbage (Brassica rapa L. subsp. chinensis)
}

\author{
Millicent G. Managa ${ }^{1}\left(\mathbb{D}\right.$, Fabienne Remize $^{2}\left(\mathbb{D}\right.$, Cyrielle Garcia $^{2}\left(\mathbb{D}\right.$ and Dharini Sivakumar ${ }^{1, *(D)}$ \\ 1 Phytochemical Food Network Research Group, Department of Crop Sciences, Tshwane University of \\ Technology, Pretoria 0183, South Africa \\ 2 Université de La Réunion, UMR C-95 QualiSud, 97715 Saint-Denis, Reunion, France \\ * Correspondence: SivakumarD@tut.ac.za; Tel.: +27-012-382-5303
}

Received: 31 July 2019; Accepted: 29 August 2019; Published: 8 September 2019

\begin{abstract}
Non-heading Chinese cabbage (Brassica rapa L. subsp. chinensis) is a widely consumed leafy vegetable by the rural people in South Africa. Traditional blanching methods $(5 \%, 10 \%$ or $20 \%$ lemon juice solutions in steam, microwave treatments and hot water bath at $95{ }^{\circ} \mathrm{C}$ ) on the changes of colour properties, phenolic metabolites, glucosinolates and antioxidant properties were investigated in this study. Blanching at $95{ }^{\circ} \mathrm{C}$ in $5 \%$ lemon juice solution maintained the chlorophyll content, reduced the difference in colour change $\Delta \mathrm{E}$, and increased the total phenolic content and the antioxidant activities (ferric reducing-antioxidant power assay (FRAP) and Trolox equivalent antioxidant capacity (TEAC) assay). The highest concentration of kaempferol-dihexoside, kaempferol-sophoroside, kaempferol hexoside, and ferulic acid was noted in samples blanched in $5 \%$ lemon juice, at $95^{\circ} \mathrm{C}$. However, concentrations of kaempferol $O$-sophoroside- $O$-hexoside was highest in raw leaf samples. Supervised Orthogonal Projections to Latent Structures Discriminant Analysis (OPLS-DA) and the UPLC-MS and chemometric approach showed the acid protocatechuoyl hexose unique marker identified responsible for the separation of the blanching treatments $\left(5 \%\right.$ lemon juice at $\left.95^{\circ} \mathrm{C}\right)$ and raw leaves. However, other unidentified markers are also responsible for the separation of the two groups (the raw leaves and the hot water moist blanched samples) and these need to be identified. Blanching at $95^{\circ} \mathrm{C}$ in $10 \%$ lemon solution significantly increased the glucosinolate sinigrin content. Overall blanching at $95{ }^{\circ} \mathrm{C}$ in $5 \%$ lemon juice solution can be recommended to preserve the functional compounds in Nightshade leaves.
\end{abstract}

Keywords: Brassica vegetables; bioactive compounds; postharvest processing; kaempferol; sinigrin

\section{Introduction}

Non-heading Chinese cabbage (Brassica rapa L. subsp. chinensis), a leafy vegetable, is widely consumed in Venda, Limpopo Province, South Africa [1]. Chinese cabbage is an indigenous African leafy vegetable and it is grown in smallholder cropping systems or in-home gardens. Since the indigenous African leafy vegetable is an inexpensive source of dietary minerals, trace elements and antioxidant phytochemicals, it can be introduced in diet diversification programmes. Chinese cabbage leaves contain Ca (1020 g kg$\left.{ }^{-1} \mathrm{FW}\right), \mathrm{Fe}\left(26 \mathrm{~g} \mathrm{~kg}^{-1} \mathrm{FW}\right)$ [2], total glucosinolates $\left(10.926 \mu \mathrm{mol} \mathrm{g}^{-1}\right.$ DW) [3], and phytochemicals such as $\beta$-carotene $\left(2305 \times 10^{-5} \mathrm{~g} \mathrm{~kg}^{-1} \mathrm{FW}\right)$ and kempferol $(0.2002$ to $0.25 \mathrm{~g} \mathrm{~kg}^{-1}$ ) [2]. Glucosinolates are the precursors of the isothiocyanates that are responsible for cancer preventative effects [4]. Thus, it has been proven in in vivo and in vitro studies that Brassicaceae species are capable of the detoxification of carcinogens and the prevention thereof due to their antioxidant activities [4]. The isothiocyanates are responsible for their anticancerogenic [5], anti-inflammatory [6] 
and antidiabetogenic [7] properties. African vegetables are bitter when eaten in raw form [8]. Therefore, traditionally Chinese cabbage is cooked using various cooking methods such as boiling, steaming or moist cooking (blanching). Traditionally cooked Chinese cabbage is consumed as a side dish with a thick starchy maize meal. However, cooked leaves of Chinese cabbage are currently used in Southern African cuisine as a filling for pastries or burgers. While cooking (thermal processing) reduces the bitterness of the Chinese cabbage [9], extensive cooking procedures can affect the composition of the functional compounds and their bioavailability, and as a result this could affect their biological activity and health benefits, more particularly, causing heat-induced myrosinase inactivation and the reduced production of isothiocyanates $[9,10]$. However, the extent of the loss of isothiocyanates is dependent on the type of processing method and the duration thereof [11].

Furthermore, in East African traditional brassica crops, the predominant flavonoid glycosides are monoacylated kaempferol di-, tri- and tetraglycosides such as kaempferol-3-O-sinapoyl-sophoroside-7-O-diglucoside and, therefore, benefit human health due to their anticancer and anti-inflammatory activities [11]. Therefore, the objectives of this study were to determine the impact of traditionally used moist cooking on colour, phenolic compounds, glucosinolates and antioxidant activity in Chinese cabbage (Brassica rapa L. subsp. chinensis).

\section{Materials and Methods}

\subsection{Plant Material}

Chinese cabbage (Brassica rapa L. subsp. chinensis) leaves were obtained from the Tshiombo irrigation scheme in Venda, Limpopo, South Africa. The leaves were harvested at the 8-leaf stage reached after 60 to 95 days of planting [1]. Leaves free from dirt and damage caused by pests or decay were selected. Thereafter, the leave samples $(50 \mathrm{~g})$ were washed with tap water and the leaves were subsequently blanched using a hot water bath, microwave and steam according to the methods described below.

\subsection{Moist Cooking Treatment}

Chinese cabbage leaves (50 g) were subjected to the following blanching treatments;

(i) blanching at $95^{\circ} \mathrm{C}$ in water bath [thermostatically regulated water bath (PolyScience, Niles, IL, USA)] for $5 \mathrm{~min}$ in water, or in $5 \%, 10 \%$ or $20 \%$ lemon juice solutions;

(ii) a microwave treatment (Defy) (household) working at $2450 \mathrm{MHz}-900 \mathrm{~W}$ for $5 \mathrm{~min}$ in water, or in $5 \%, 10 \%$ or $20 \%$ lemon juice solutions;

(iii) steaming in stainless steel steamer pot for $5 \mathrm{~min}$ in water or in $5 \%, 10 \%$ or $20 \%$ lemon juice solutions at $100^{\circ} \mathrm{C}$.

The $\mathrm{pH}$ of the $5 \%, 10 \%$ or $20 \%$ solutions were $4.2-4.4,3.3-3.4$ and $2.2-2.5$, respectively.

Thereafter the samples from the selected treatments were subjected to a detailed analysis of the antinutritive compounds, total phenols, and phenolic metabolites and antioxidant properties. The selected samples were snap frozen in liquid nitrogen and stored at $-80^{\circ} \mathrm{C}$ for all the biochemical analyses. The raw snap frozen samples were included as the control in this study. Each treatment had a set of ten replicates.

\subsection{Chemicals}

Acetone hexane, dimethylsulfoxide (DMSO), methanol, acetonitrile, formic acid, chlorogenic acid $(\geq 95 \%)$, catechin $(\geq 95 \%)$, luteolin ( $\geq 95 \%)$, epicatechin $(\geq 95 \%)$ and rutinn $(\geq 95 \%)$, sodium acetate $(\geq 95 \%)$, ferulic acid $(\geq 95 \%)$, rutin $(\geq 95 \%)$, kaempferol $O$-sophoroside-O-hexoside $(\geq 95 \%)$, myrectin-O-arabinoside ( $\geq 95 \%), 2,4,6$-tris(2-pyridyl)-1,3,5-triazine, hydrochloric acid $(\mathrm{HCl})$, ferric chloride $\left(\mathrm{FeCl}_{3}\right)$, Trolox, 2,2'-azobis(2-amidinopropane) hydrochloride (ABAP), 2,2'-azinobis(3-ethylbenzothiazoline-6-sulfonate), phosphate, sodium chloride ( $\mathrm{NaCl}$ ), ammonium 
hydroxide $\left(\mathrm{NH}_{4} \mathrm{OH}\right)$, Folin-Ciocalteu reagent, sodium carbonate $\left(\mathrm{Na}_{2} \mathrm{CO}_{3}\right)$, gallic acid, 1 methoxyglucobrassicin, 4-methoxyglucobrassicin and sinigrin were purchased from Sigma Aldrich, Johannesburg, South Africa.

\subsection{Colour Measurement}

The colour of the Chinese cabbage leaf was measured using a Minolta CR-400 chromameter (Minolta, Osaka, Japan). In the International Commission on Illumination (CIE) CIE colour system, colour coordinate $a^{*}$ can be related to the red and green colours when it has a positive or negative value. Similarly, colour coordinate $b^{*}$ can be described as a yellow colour when it is positive. The colour changes $(\Delta E)$ were calculated using the following formula [12].

$$
\mathrm{E}_{\mathrm{ab}}^{*}=\sqrt{\left(\mathrm{L}_{1}^{*}-\mathrm{L}_{2}^{*}\right)^{2}+\left(\mathrm{a}_{1}^{*}-\mathrm{a}_{2}^{*}\right)^{2}+\left(\mathrm{b}_{1}^{*}-\mathrm{b}_{2}^{*}\right)^{2}}
$$

where $L_{1}{ }^{*}, a_{1}{ }^{*}, b_{1}{ }^{*}$ are the values for raw sample values. $L_{2}{ }^{*}, a_{3}{ }^{*}$, and $b_{3}{ }^{*}$ are the values of the sample subjected to different blanching treatments. Measurements were taken at three points on the per replicate and ten replicate samples per treatment were used for the determination of colour changes.

\subsection{Chlorophyll}

The chlorophyll a ( $C h l a) b(C h l b)$, and total chlorophyll were determined without modifications using leaf samples $(0.2 \mathrm{~g})$ ground with $2 \mathrm{~mL}$ of acetone and hexane 4:6 $(v / v)$ and extracted for $2 \mathrm{~h}$. Afterwards, the sample mixture was centrifuged for $10 \mathrm{~min}$ at $4{ }^{\circ} \mathrm{C}(9558 \times \mathrm{g})$. Thereafter, the resulting supernatant was decanted, and a portion of the solution was measured at 470, 646 and $662 \mathrm{~nm}$ (Biochrom Anthos Zenyth 200 Microplate Reader; SMM Instruments, Biochrom Ltd., Johannesburg, South Africa). The Chl $a$ and Chl $b$ contents were determined according to equations: Chl $a=15.65 A 662$ $-7.340 A 646$ and $C h l b=27.05 A 646-11.21 A 662$. The content of $C h l a+C h l b$ gives the total chlorophyll content and it was expressed in $\mathrm{mg}$ per $100 \mathrm{~g}$ on a fresh weight basis [2].

\subsection{Total Phenol and Predominant Metabolic Profile}

\subsubsection{Total Phenol Content}

Snap frozen Chinese cabbage $(0.2 \mathrm{~g})$ was homogenized in $2 \mathrm{~mL}$ of $80 \%$ methanol $(v / v)$, and then centrifuged at $10,000 \times \mathrm{g}$ for $10 \mathrm{~min}$ at $4{ }^{\circ} \mathrm{C}$ using Hermle Labortechnik, Germany. Total phenolic content was determined using the modified method of Singleton, Orthofer and Lamuella-Raventós (1999). An aliquot of $9 \mu \mathrm{L}$ of supernatant extract was mixed with $109 \mu \mathrm{L}$ of Folin-Ciocalteu reagent then followed by $180 \mu \mathrm{L}$ of $7.5 \% \mathrm{Na}_{2} \mathrm{CO}_{3}$. The total of the phenolic compounds was calculated using gallic acid and the results were expressed as mg $100 \mathrm{~g}^{-1}$ gallic acid equivalents (GAEs) on a fresh weight basis.

\subsubsection{Predominant Metabolic Profile}

The detection and quantification of predominant metabolites were carried out using the Quadrupole time-of-flight (QTOF) mass spectrometer (MS) UPLC-Q-TOF/MS (Waters, Milford, MA, USA). The conditions for separation of the phenolic compounds are similar to Ndou et al. [13].

Due to the unavailability of the calibration standards for all the compounds, the identification was carried out by means of quantification against the calibration curves set up using chlorogenic acid, catechin, luteolin, epicatechin and rutin as described by Stander et al. [14]. Four different cocktails were made at each level to facilitate the identification of the isomers and compounds with similar elemental formulas as described by Stander et al. [14]. Cocktails were prepared in methanol (50\%) in $\mathrm{H}_{2} \mathrm{O}$ containing formic acid (1\%) solution. The main peaks in each chromatogram were quantified by setting up the TargetLynx processing method (part of MassLynx). Extracted mass chromatograms were defined for each compound, based on the retention time and accurate mass obtained from the 
high-resolution mass spectrometer [13]. Due to the unavailability of the calibration standards for all the compounds identified, these were semi-quantitatively measured against calibration curves set up using chlorogenic acid, catechin, luteolin, epicatechin and rutin [13]. Extracted mass-retention time pairs for each compound were defined in the TargetLynx method and the closest eluting calibration compound (chlorogenic acid, catechin, epicatechin, or rutin) was set as the calibration reference compound. A range of calibration standards containing from 1 to $200 \mathrm{mg} / \mathrm{L}$ chlorogenic acid, catechin, epicatechin and rutin were injected using the same method of Stander et al. [14] for the samples. The data was then reprocessed using the established TargetLynx method to produce integrated peak areas for each compound, which were then interpolated off the calibration curves for the reference compounds. Based on the masses of the plant material extracted, the volumes of extraction solvent used, and the dilutions employed, the concentrations of the compounds in the plant material was calculated by the TargetLynx software as previously shown by Stander et al. [14].

Chlorogenic acid, catechin, epicatechin ferulic acid, rutin, ranging from 1 to $200 \mathrm{mg} / \mathrm{L}$ were injected as calibration standards using the same method of Stander et al. [14]. The data was then reprocessed using the established TargetLynx method to produce integrated peak areas for each compound, which were then interpolated off the calibration curves for the reference compounds. The concentrations of the compounds in the plant material was calculated by the TargetLynx software based on the masses of the extracted plant material, the volumes of extraction solvent used, and the dilutions employed as described previously in our research [13].

\subsection{Total Antioxidant Capacities Were Determined Using the Following Assays}

The ferric reducing-antioxidant power assay was executed following the method described by Mpai et al. [15]. Nightshade leaf samples $(0.2 \mathrm{~g})$ were homogenized in $2 \mathrm{~mL}$ of sodium acetate buffer at a $\mathrm{pH}$ of 3.6. The ferric-reducing ability was estimated by mixing a $15 \mu \mathrm{L}$ aliquot of leaf extract, with $220 \mu \mathrm{L}$ of FRAP reagent solution (10 $\mathrm{mmol} \mathrm{L}^{-1}$ 2,4,6-tris(2-pyridyl)-1,3,5-triazine (TPTZ)) acidified with concentrated $\mathrm{HCl}$, and $20 \mathrm{mmol} \mathrm{L}^{-1} \mathrm{FeCl}_{3}$ ]. The absorbance was read at $593 \mathrm{~nm}$ and the reducing antioxidant power content was calculated using a standard curve of Trolox and expressed $\mu \mathrm{mol}$ Trolox equivalent antioxidant capacity (TEAC) $\mathrm{g}^{-1} \mathrm{FW}$.

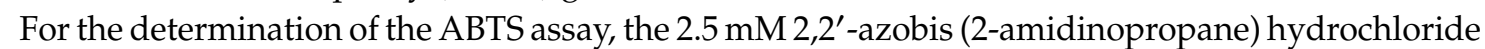

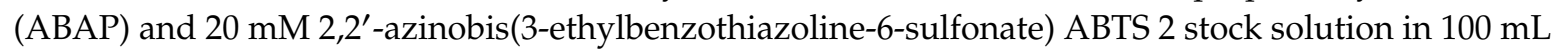
of phosphate buffer ( $100 \mathrm{mM}$ phosphate and $150 \mathrm{mM} \mathrm{NaCl}, \mathrm{pH} 7.4)$ were mixed and incubated at $60^{\circ} \mathrm{C}$ for 6 min without any modifications as described by Egea, Sánchez-Bel, Romojaro, and Pretel [16].

To produce the ABTS radical anion, the mixture was held in darkness for $16 \mathrm{~h}$ at $25^{\circ} \mathrm{C}$ and afterwards diluted with $0.1 \mathrm{mM}$ phosphate buffer $(\mathrm{pH} 7.0)$ to obtain an absorbance at $734 \mathrm{~nm}$ $(1.1 \pm 0.002$ units). Thereafter, the radical solution $(285 \mu \mathrm{L})$ was added to the sample extract (15 $\mu \mathrm{L}$ ) and the decrease in absorbance observed at $734 \mathrm{~nm}$ for $6 \mathrm{~min}$ was used to calculate the Trolox equivalent antioxidant capacity (TEAC). Calibration curves were constructed for each assay using different concentrations $(0-20 \mathrm{mg}$ ) of Trolox. The antioxidant activity (ABTS assay) was expressed as $\mu \mathrm{mg}$ of TEAC $\mathrm{g} \mathrm{FW}^{-1}$.

\subsection{Glucosinolate}

Samples were prepared by extracting $5 \mathrm{~g}$ of sample with $15 \mathrm{~mL}$ of extraction solvent $(50 \%$ $\mathrm{MeOH}$ in $0.1 \%$ formic acid). After sonication in an ultrasonic bath for $1 \mathrm{~h}$, the samples were centrifuged at $14,000 \times g$ for $5 \mathrm{~min}$. A clear sample was transferred to $2 \mathrm{~mL}$ glass vials for analysis. A Waters Synapt G2 Quadrupole time-of-flight (QTOF) mass spectrometer (MS) connected to a Waters Acquity ultra-performance liquid chromatograph (UPLC) (Waters, Milford, MA, USA) was used for high-resolution UPLC-MS analysis. Electrospray ionization was used in the negative mode with a cone voltage of $15 \mathrm{~V}$, desolvation temperature of $275^{\circ} \mathrm{C}$, desolvation gas at $650 \mathrm{~L} \mathrm{~h}^{-1}$, and the rest of the MS settings optimized for best resolution and sensitivity. Data were acquired by scanning from $\mathrm{m} / \mathrm{z}$ 100 to $1200 \mathrm{~m} / \mathrm{z}$ in the resolution mode as well as in the mass spectrometry (MS) E represents collision 
energy MSE mode. In the MSE mode, two channels of MS data were acquired—one at a low collision energy $(4 \mathrm{~V})$ and the second using a collision energy ramp (40-100 V) - to obtain fragmentation data as well. Leucine enkaphalin was used as the lock mass (reference mass) for accurate mass determination and the instrument was calibrated with sodium formate. Separation was achieved on a Waters Acquity $\mathrm{BEH}$ (Ethylene-bridged hybrid) $\mathrm{C} 18,2.1 \times 100 \mathrm{~mm}, 1.7 \mu \mathrm{m}$ column. An injection volume of $2 \mu \mathrm{L}$ was used and the mobile phase consisted of $0.1 \% \mathrm{NH}_{4} \mathrm{OH}$ in water (solvent $\mathrm{A}$ ) and acetonitrile containing $0.1 \% \mathrm{NH}_{4} \mathrm{OH}$ acid as solvent $\mathrm{B}$. The gradient started at $100 \%$ solvent $\mathrm{A}$ for $0.3 \mathrm{~min}$ and changed to $3 \% \mathrm{~B}$ over $3 \mathrm{~min}$ in a linear way. It then went to $28 \% \mathrm{~B}$ at $9 \mathrm{~min}$, followed by $100 \% \mathrm{~B}$ after $9.1 \mathrm{~min}$, with a wash step of $0.9 \mathrm{~min}$ at $100 \% \mathrm{~B}$, followed by re-equilibration to initial conditions for $3 \mathrm{~min}$. The flow rate was $0.3 \mathrm{~mL} \mathrm{~min}{ }^{-1}$ and the column temperature was maintained at $55{ }^{\circ} \mathrm{C}$. Glucosinolates were quantified in a relative fashion against sinigrin, with calibration standards ranging from 10 to $100 \mathrm{mg} \mathrm{L}^{-1}$. Other glucosinolates, including 1 and 4-methoxyglucobrassicin, were identified on the basis of accurate mass elemental composition and fragmentation patterns.

\subsection{Statistical Analysis}

A completely randomized design was adopted with ten replicates per treatment and the experiments were repeated twice. A factorial type $\left(4 \times 4\right.$ or $\left.4^{2}\right)$ experiment was conducted, which includes the different types of moist cooking and the control (raw, steam, microwave and hot water bath) and the type of blanching media (water, $5 \%$ lemon juice, $10 \%$ lemon juice or $20 \%$ lemon juice) on the change of colour difference, chlorophyll content. Two-way analysis of variance (ANOVA) was used to analyse the mean differences between different blanching treatments at a significance level of $p<0.05$. Interaction between "the moist cooking methods" and the "type of blanching media" was investigated in this study for parameters such as colour difference and chlorophyll content. After selecting the best method of moist cooking (hot water bath) the different types of blanching media (water, $5 \%$ lemon juice, $10 \%$ lemon juice), one-way ANOVA was performed on total phenolic compounds, predominant phenolic compounds, antioxidant activities (FRAP and TEAC assay) and sinigrin content. Means were compared among treatments by the least significant difference (LSD) test with $p<0.05$ considered to indicate statistical significance. The data were analysed using the Genstat for Windows 13th Edition (2010) (VSN International, Hempstead, UK).

\section{Results}

\subsection{Colour Difference, Chlorophyll Content}

Moist cooking blanching (dipping) in $5 \%$ or $10 \%$ lemon juice solution, at $95^{\circ} \mathrm{C}$ in a water bath, significantly minimised the difference in colour change $(\Delta E)$ (Figure 1). All the other moist cooking blanching treatments adopted in this study revealed a significantly high difference in colour change $(\Delta E)$ due to the olive brown colour of the leaves (Figure 1). The total chlorophyll content was significantly reduced during steam, hot water bath and microwave blanching when $20 \%$ lemon juice solution was used as the blanching medium.

Similarly, blanching in $5 \%$ lemon juice solution, at $95^{\circ} \mathrm{C}$ in a water bath, significantly retained the total chlorophyll content followed by the $5 \%$ lemon juice solution (water bath) at $95{ }^{\circ} \mathrm{C}$ (Figure 2). Overall, microwave and steam blanching in both 10 and $20 \%$ lemon solution significantly reduced the total chlorophyll content (Figure 2).

Therefore, Chinese cabbage leaves blanched in 5\% or $10 \%$ lemon juice solution and water, as a blanching medium at $95{ }^{\circ} \mathrm{C}$ in a hot water bath, were selected for further analysis of phenolic compounds and antioxidant activity. 


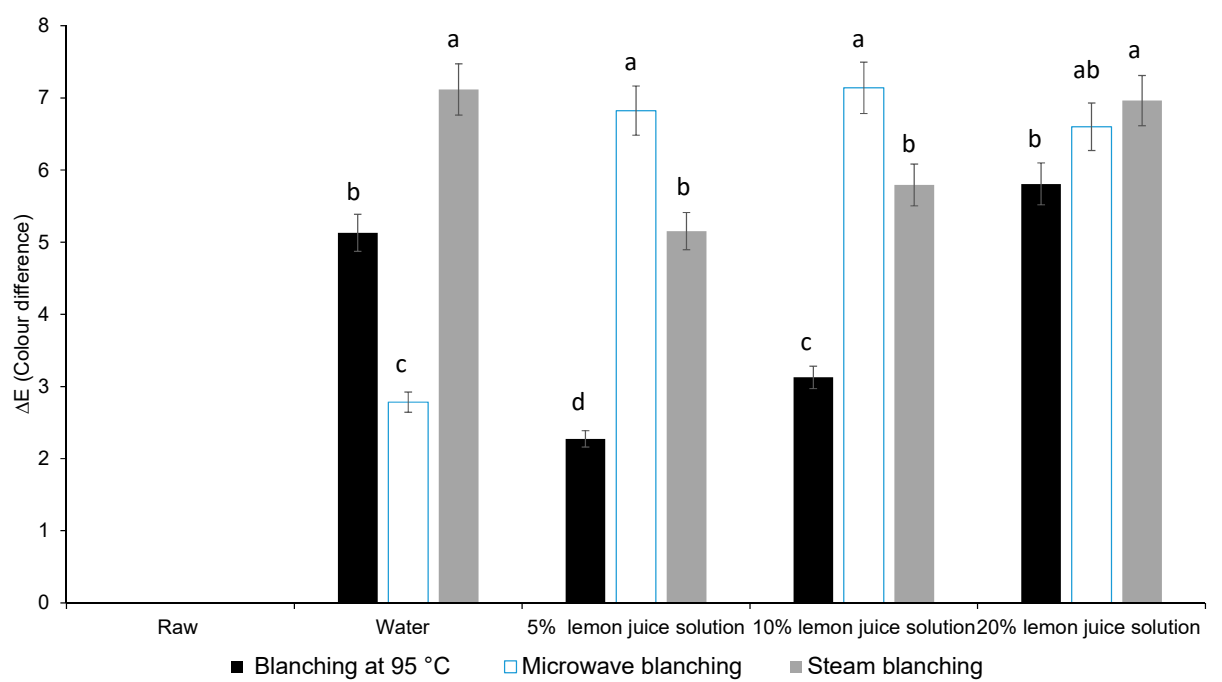

Figure 1. Effect of different types of moist cooking blanching treatments on colour difference $(\Delta E)$ in Chinese cabbage leaves. Bars with the same alphabetic letter per moist cooking treatment are not significantly different at $p<0.05)$.

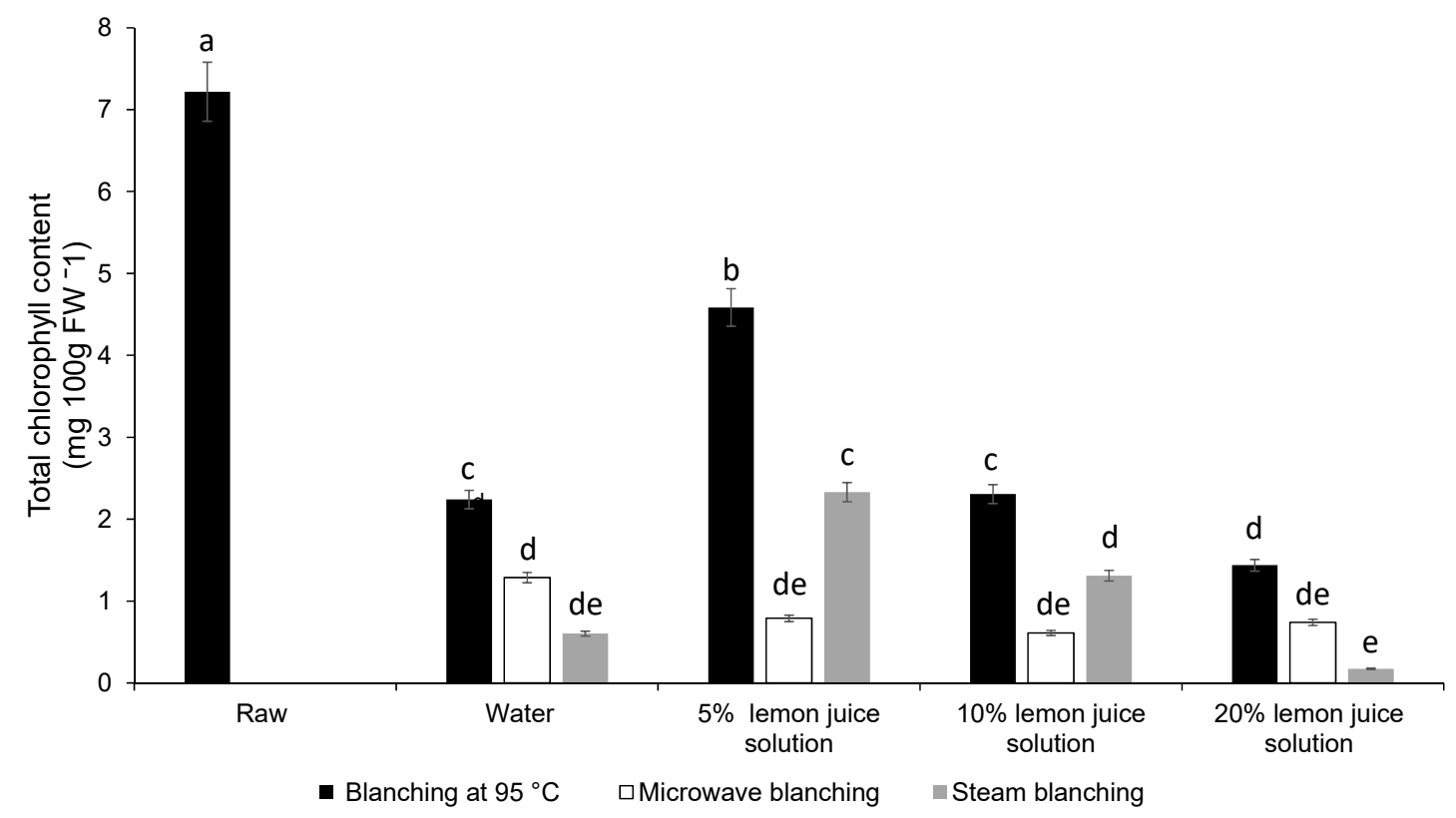

Figure 2. Effect of different types of moist cooking blanching treatments on total chlorophyll content in Chinese cabbage leaves. Bars with the same alphabetic letter are not significantly different at $p<0.05$ ).

\subsection{Total Phenolic Compounds and Phenolic Components}

Blanching in a water bath at $95^{\circ} \mathrm{C}$ using water as a blanching medium significantly increased the total phenolic content in Chinese cabbage compared to the raw leaves (Figure 3). However, with an increasing concentration of lemon juice, a declining trend in total phenolic content was noted (Figure 3). When $10 \%$ lemon juice was used as blanching medium, the total phenolic content was maintained at similar levels as raw leaves (Figure 3).

Total ion chromatograms of the Chinese cabbage samples subjected to different blanching treatments and blanching media in the Electrospray ionization (ESI) mode by UPLC-Q-TOF/MS were illustrated in Table 1 and Figure S1. 


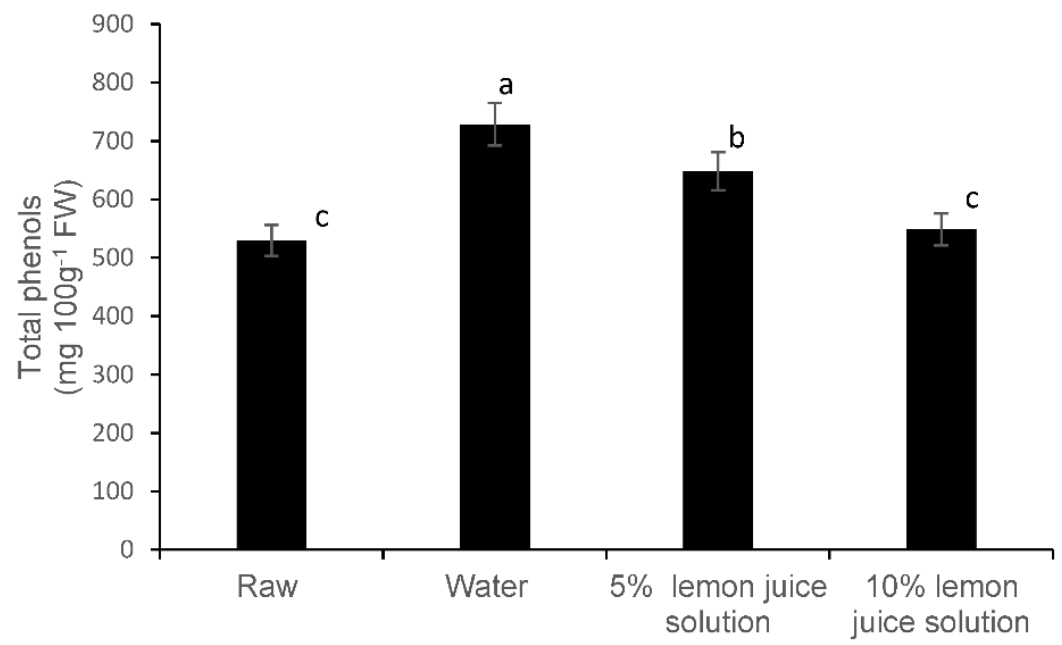

Figure 3. Effect of different types of moist cooking blanching treatments on total phenol content in Chinese cabbage leaves. Bars with the same alphabetic letter are not significantly different at $p<0.05$.

Table 1. Tentative peak assignment of the metabolites contained in Chinese cabbage leaves subjected to moist cooking blanching treatments using different types of blanching medium.

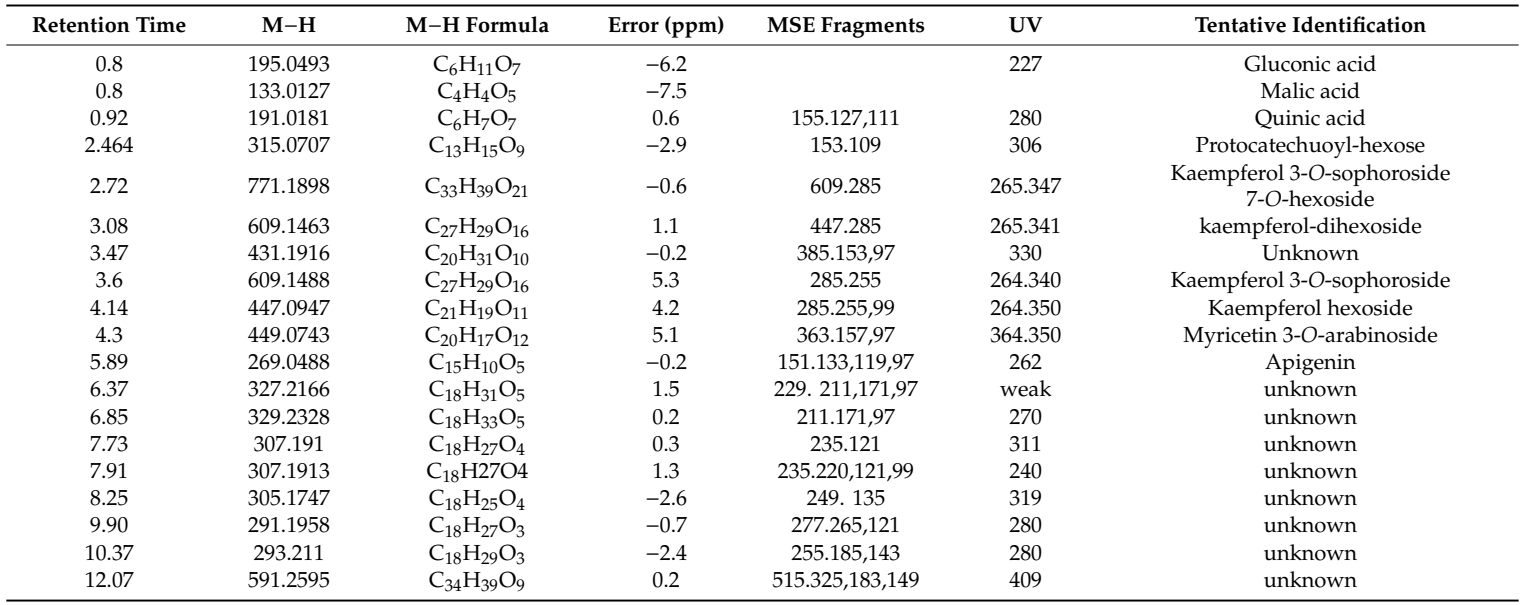

The differences between the phenolic metabolic profiles of the different hot water bath blanching treatments and blanching media compared with that of the raw leaves were evident when using an unsupervised Principal Component Analysis (PCA) approach using the data generated by the UPLC-Q-TOF/MS analysis. Figure 4A showed the PC 1 and PC 2 explaining $41 \%$ and $17 \%$ of the variance and illustrating good statistical separation among the various adopted moist cooking blanching treatments. The PCA plot, which has three groups based on the metabolites, demonstrated that the blanching treatments influenced the metabolites in Chinese cabbage leaves. Group 1 included the hot water bath blanching at $95^{\circ} \mathrm{C}$ using water or $5 \%$ lemon juice solution as the blanching medium for 5 min, and Group 2 included blanching using a hot water bath with $10 \%$ lemon juice solution as the blanching medium for $5 \mathrm{~min}$ (Figure 4A). However, to explain the two groups blanching in a hot water bath and steaming in water or $5 \%$ solution of lemon juice and to identify the potential characteristic markers (metabolites) responsible for discrimination between the treatments, supervised Orthogonal Projections to Latent Structures Discriminant Analysis (OPLS-DA) was performed. The potential markers were chosen based on the weightage of their contribution towards the variation and correlation within the data set. This model showed greater reliability and validity (variance recorded at $8.98 \%$ ) (Figure 4A). In the S-plot, the points are Exact Mass/Retention Time pairs (EMRTs) plotted by covariance (x-axis) and correlation (y-axis) values (Figure 4B). The S-plot helped to identify the EMRT pairs that contributed towards the most significant difference between the raw Chinese cabbage leaves and those 
subjected to hot water blanching treatment (Figure 4). The loadings from a two-class OPLS-DA model (Hot water vs. Raw) are shown here in an S-Plot format for Raw (Figure 5). The points are Exact Mass/Retention Time pairs (EMRTs) plotted by covariance (x-axis) and correlation (y-axis) values. The upper right quadrant of the S-plot shows those components which are elevated in the control group, while the lower left quadrant shows components elevated in the treated group. The farther along the x-axis, the greater the contribution to the variance between the groups, while, the farther the $\mathrm{Y}$ axis, the higher the reliability of the analytical result. Some of the most important EMRTs are tabulated and plotted below. The candidate markers responsible for the observed trend in the S-plot are shown in Tables 2 and 3. Based on Tables 2 and 3, the protocatechuoyl-hexose is the only phenolic compound successfully identified as a marker of the difference in the phenolic profiles of raw Chinese cabbage. This compound was not found in the blanched leaves. This was confirmed by the quantitative analysis that showed a disappearance of this compound in hot water blanching. Other unidentified compounds (markers) that were responsible for the observed separation will be identified as part of our future work.

The UPLC-Q-TOF/M analysis helped to identify 10 compounds: gluconic acid ( $\mathrm{m} / \mathrm{z}$ 195.0493, $\lambda$ 227), malic acid ( $m / z$ 133.0127), quinic acid $(m / z 191.0181, \lambda 280)$, protocatechuoyl-hexose $(m / z$ $315.0707, \lambda$ 306), kaempferol 3-O-sophoroside 7-O-hexoside $(m / z, \lambda 265.347)$, kaempferol-dihexoside $(m / z$ 609.1463, $\lambda$ 265.341), kaempferol 3-O-sophoroside $(m / z 609.1488 \lambda 264.340)$, kaempferol hexoside $(m / z 447.0947, \lambda 264,350)$, and myricetin 3-O-arabinoside $(m / z 449.0743, \lambda 364,350)$, as shown in Table 1 and Figure S1.

Table 2. Exact mass/retention time pairs responsible for the separation of raw Chinese cabbage leaves.

\begin{tabular}{ccccc}
\hline & Retention Time & Mass & P(1)P & p(corr)(1)P \\
\hline 9.92_291.1957 & 9.92 & 291.1957 & 0.237452 & 0.971414 \\
10.38_293.2110 & 10.38 & 293.211 & 0.2061 & 0.995988 \\
8.27_305.1753 & 8.27 & 305.1753 & 0.231893 & 0.998607 \\
7.74_307.1916 & 7.74 & 307.1916 & 0.168101 & 0.991243 \\
2.46_315.0707 & 2.46 & 315.0707 & 0.2004 & 0.998301 \\
6.37_327.2171 & 6.37 & 327.2171 & 0.237674 & 0.87965 \\
6.85_329.2318 & 6.85 & 329.2318 & 0.146947 & 0.969433 \\
3.85_385.1121 & 3.85 & 385.1121 & 0.166316 & 0.981166 \\
3.47_431.1912 & 3.47 & 431.1912 & 0.19889 & 0.989573 \\
3.47_483.1625 & 3.47 & 483.1625 & 0.13382 & 0.953158 \\
10.88_555.2839 & 10,88 & 555.2839 & 0.175476 & 0.902287 \\
\hline
\end{tabular}

Table 3. Exact mass/retention time pairs responsible for the separation of all hot water-blanched Chinese cabbage leaves irrespective of the type of blanching medium.

\begin{tabular}{ccccc}
\hline Primary ID & Retention Time & Mass & P(1)P & p(corr)(1)P \\
\hline 4.02_193.0497 & 4.02 & 193.0497 & -0.21239 & -0.912351 \\
4.01_223.059 & 4.01 & 223.0599 & -0.29435 & -0.984697 \\
3.48_325.0552 & 3.48 & 325.0552 & -0.15576 & -0.984697 \\
4.01_339.0712 & 4.01 & 339.0712 & -0.19615 & -0.984697 \\
2.90_963.2412 & 2.90 & 963.2412 & -0.25714 & -0.984697 \\
3.13_977.2561 & 3.13 & 977.2561 & -0.16666 & -0.984697 \\
\hline
\end{tabular}




\section{Scores Comp[1] vs. Comp[2] colored by Group (original)}

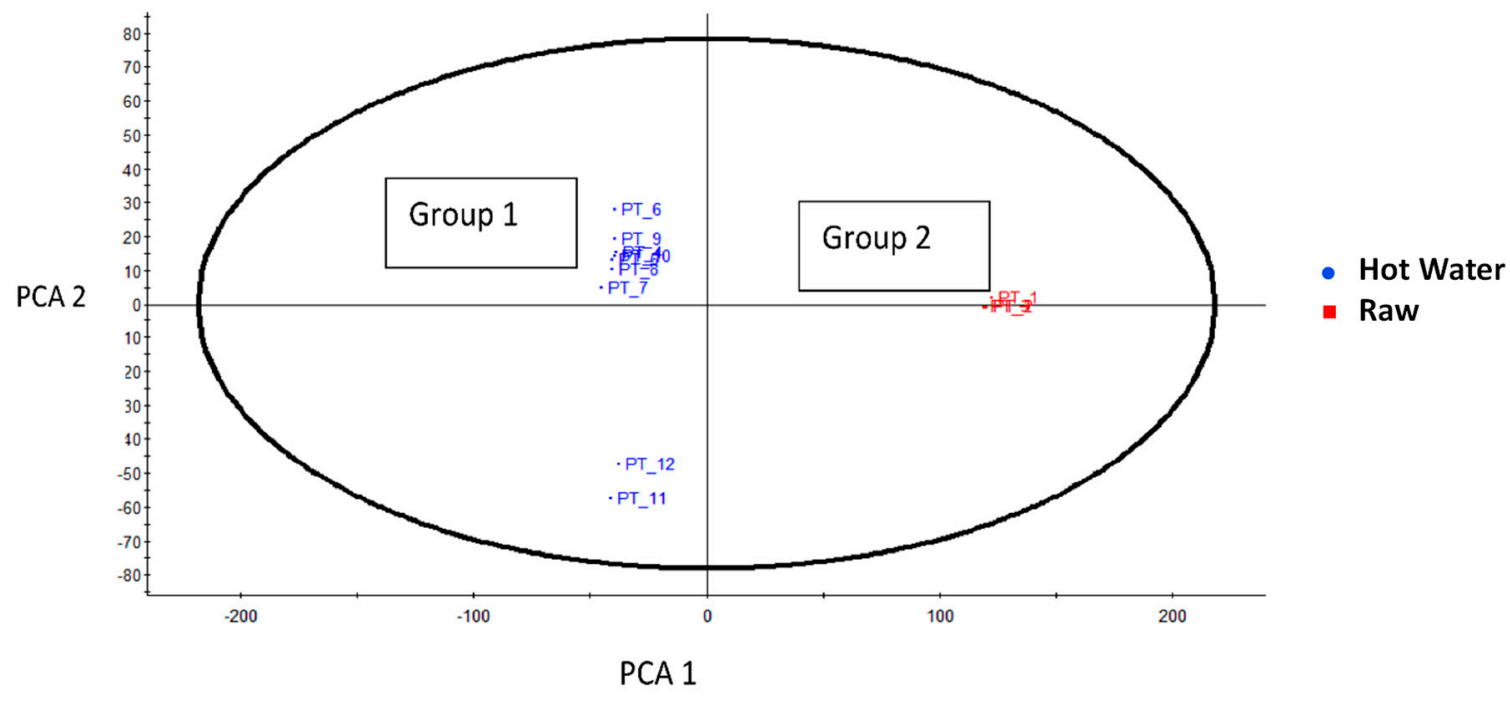

(A)

Loadings Comp[1] vs. Comp[2] (Hot water $=-1$, Raw $=1)$

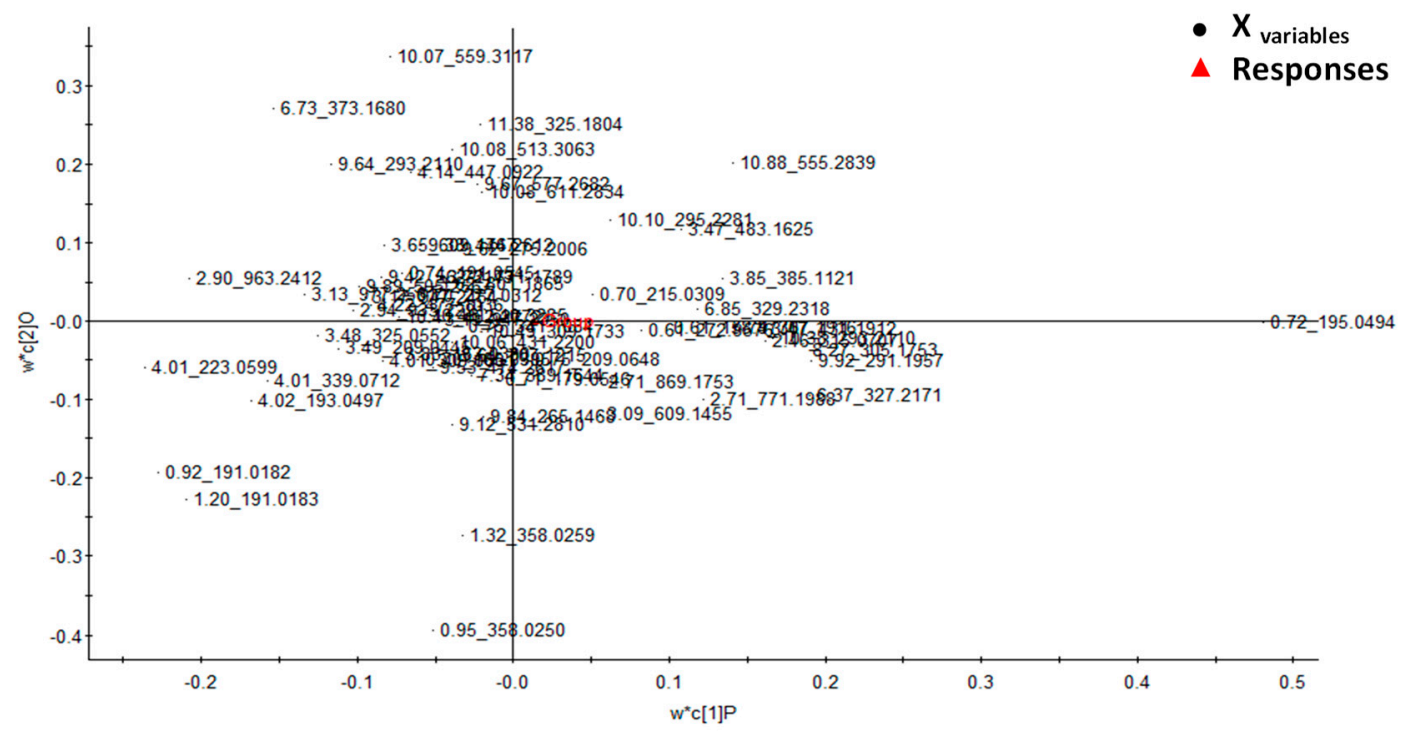

(B)

Figure 4. (A) Score plot of principal component analysis (unsupervised) based on UPLC-Q-TOF/MS spectra of different moist cooking blanching treatments. Group 1 included the hot water bath blanching at $95{ }^{\circ} \mathrm{C}$ using water or $5 \%$ or $10 \%$ lemon juice as blanching medium for $5 \mathrm{~min}$. Group 2 included the raw leaves. (B) Loading of Principal component analysis based on UPLC-Q-TOF/MS spectra of different moist cooking blanching treatments. 


\section{S-Plot $($ Hot water $=-1$, Raw $=1)$}

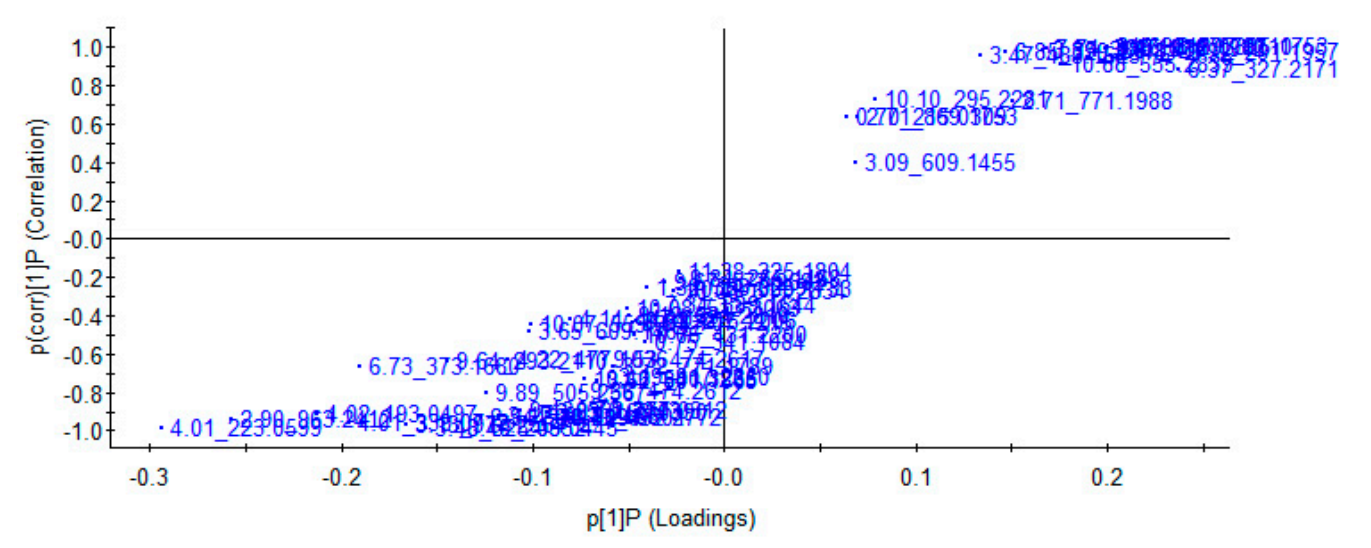

EZinfo 2 - ChineseCabbage_PT_TUT_1903213 (M5: OPLS-DA) - 2019-08-14 12:51:18 (UTC+2)

Figure 5. Score plot of orthogonal partial least squares discriminant analysis of ultra-performance liquid-quadrupole time-of-flight (QTOF) mass spectrometer (MS) (UPLC-Q-TOF/MS) spectra of hot water bath blanching treatments and raw samples. Each sample set includes three replicates.

The UPLC-Q-TOF/MS quantified phenolic profile obtained for raw Chinese cabbage showed the highest content of quininic acid $\left(209 \mathrm{mg} \mathrm{kg}^{-1}\right)$, kaempferol $O$-sophoroside- $O$-hexoside (50.4 $\left.\mathrm{mg} \mathrm{kg}^{-1}\right)$, ferulic acid (50.3 $\left.\mathrm{mg} \mathrm{kg}^{-1}\right)$ and protocatechuoyl-hexose $\left(46 \mathrm{mg} \mathrm{kg}^{-1}\right)$, followed by kaempferol-dihexoside $\left(8.0 \mathrm{mg} \mathrm{kg}^{-1}\right)$, kaempferol hexoside $\left(20.8 \mathrm{mg} \mathrm{kg}^{-1}\right)$ and myrectin-O-arabinoside $\left(20.3 \mathrm{mg} \mathrm{kg}^{-1}\right)$ (Table 4). Different concentrations of lemon juice blanching media affected the concentrations of the phenolic compounds (Table 4). Hot water bath blanching using 10\% lemon juice as the blanching medium significantly reduced the concentration of kaempferol $\mathrm{O}$-sophoroside-O-hexoside, kaempferol-dihexoside, kaempferol-sophoroside, kaempferol hexoside and myrectin-O-arabinoside compared to the raw Chinese cabbage samples (Table 4). Therefore, using $10 \%$ lemon juice blanching medium at $95{ }^{\circ} \mathrm{C}$ must be avoided. However, a 5 -fold increase in the quinic acid concentration was noted in samples blanched in water or $5 \%$ lemon juice at $95^{\circ} \mathrm{C}$ compared with the raw samples (Table 4), whereas, the $10 \%$ lemon juice blanching medium at $95^{\circ} \mathrm{C}$ showed an 8 -fold increase in quinic acid compared to the raw samples (Table 4). The ferulic acid concentration was significantly the highest during blanching in water or $5 \%$ lemon juice at $95{ }^{\circ} \mathrm{C}$. Protocatechuoyl hexose was detected in only the raw samples (Table 4). The highest concentrations of kaempferol-dihexoside, kaempferol hexoside were obtained during blanching in $5 \%$ lemon juice at $95^{\circ} \mathrm{C}$ (Table 4 ), whereas the highest concentration of kaempferol-dihexoside, kaempferol-sophoroside and kaempferol hexoside was noted in samples blanched in $5 \%$ lemon juice at $95^{\circ} \mathrm{C}$ (Table 4). The highest concentrations of kaempferol $\mathrm{O}$-sophoroside- $\mathrm{O}$-hexoside and myrectin- $\mathrm{O}$-arabinoside were detected in the raw $\mathrm{Chinese}$ cabbage samples (Table 4). The ferulic acid content did not change significantly when water or $5 \%$ lemon water was used as the blanching medium (Table 4). 
Table 4. Effect of different types of moist cooking blanching treatments using hot water bath blanching at $95^{\circ} \mathrm{C}$ on predominant phenolic compounds in Chinese cabbage leaves.

\begin{tabular}{|c|c|c|c|c|c|c|c|c|}
\hline & Quinic Acid & Protocatechuoyl Hexose & $\begin{array}{c}\text { Kaempferol } \\
O \text {-Sophoroside-O-Hexoside } \\
\left(\mathrm{mg} \mathrm{kg}^{-1}\right)\end{array}$ & Kaempferol-Dihexoside & Ferulic Acid & Kaempferol-Sophoroside & Kaempferol Hexoside & Myrectin-O-Arabinoside \\
\hline Raw & $209.8 \pm 0.02^{c, *}$ & $46.0 \pm 0.07^{a}$ & $50.4 \pm 0.01^{a}$ & $27.7 \pm 0.05^{b}$ & $8.0 \pm 0.03^{c}$ & $20.8 \pm 0.02^{b}$ & $20.3 \pm 0.06^{b}$ & $13.4 \pm 0.03^{\mathrm{a}}$ \\
\hline Water & $709.7 \pm 0.04 \mathrm{~b}$ & $0.0 \pm 0.00^{\mathrm{b}}$ & $31.8 \pm 0.06^{\mathrm{c}}$ & $19.9 \pm 0.08^{\mathrm{c}}$ & $462.9 \pm 0.10^{a}$ & $28.9 \pm 0.05^{b}$ & $28.9 \pm 0.03^{b}$ & $8.5 \pm 0.01^{\mathrm{b}}$ \\
\hline $5 \%$ lemon juice solution & $765.9 \pm 0.01 \mathrm{~b}$ & $0.0 \pm 0.00^{\mathrm{b}}$ & $46.4 \pm 0.04^{b}$ & $37.1 \pm 0.01^{\mathrm{a}}$ & $463.9 \pm 0.04{ }^{a}$ & $73.6 \pm 0.08^{a}$ & $69.9 \pm 0.02^{\mathrm{a}}$ & $6.9 \pm 0.07^{c}$ \\
\hline $10 \%$ lemon juice solution & $1067.2 \pm 0.05$ a & $0.0 \pm 0.00^{b}$ & $17.2 \pm 0.03^{\mathrm{d}}$ & $12.9 \pm 0.04^{\mathrm{d}}$ & $101.4 \pm 0.03^{b}$ & $1.7 \pm 0.03 \mathrm{c}$ & $0.8 \pm 0.12^{\mathrm{c}}$ & $2.1 \pm 0.02^{\mathrm{d}}$ \\
\hline
\end{tabular}

Means with the same alphabetic letter for a specific phenolic compound are not significantly different at $p<0.05, *$ standard deviation. 


\subsection{Antioxidant Activity}

The FRAP and TEAC assays showed that the leaf samples blanched with $0.5 \%$ lemon water as a blanching medium had the strongest antioxidant capacity compared with the other samples and the raw leaves (Figure 6A,B). At the same time, the lowest antioxidant activity was noted in the unblanched leaf samples (raw leaves) (Figure 6). Moreover, the antioxidant capacity of the samples blanched with $10 \%$ lemon juice medium was the lowest among the three tested blanching treatments (Figure 6A,B).
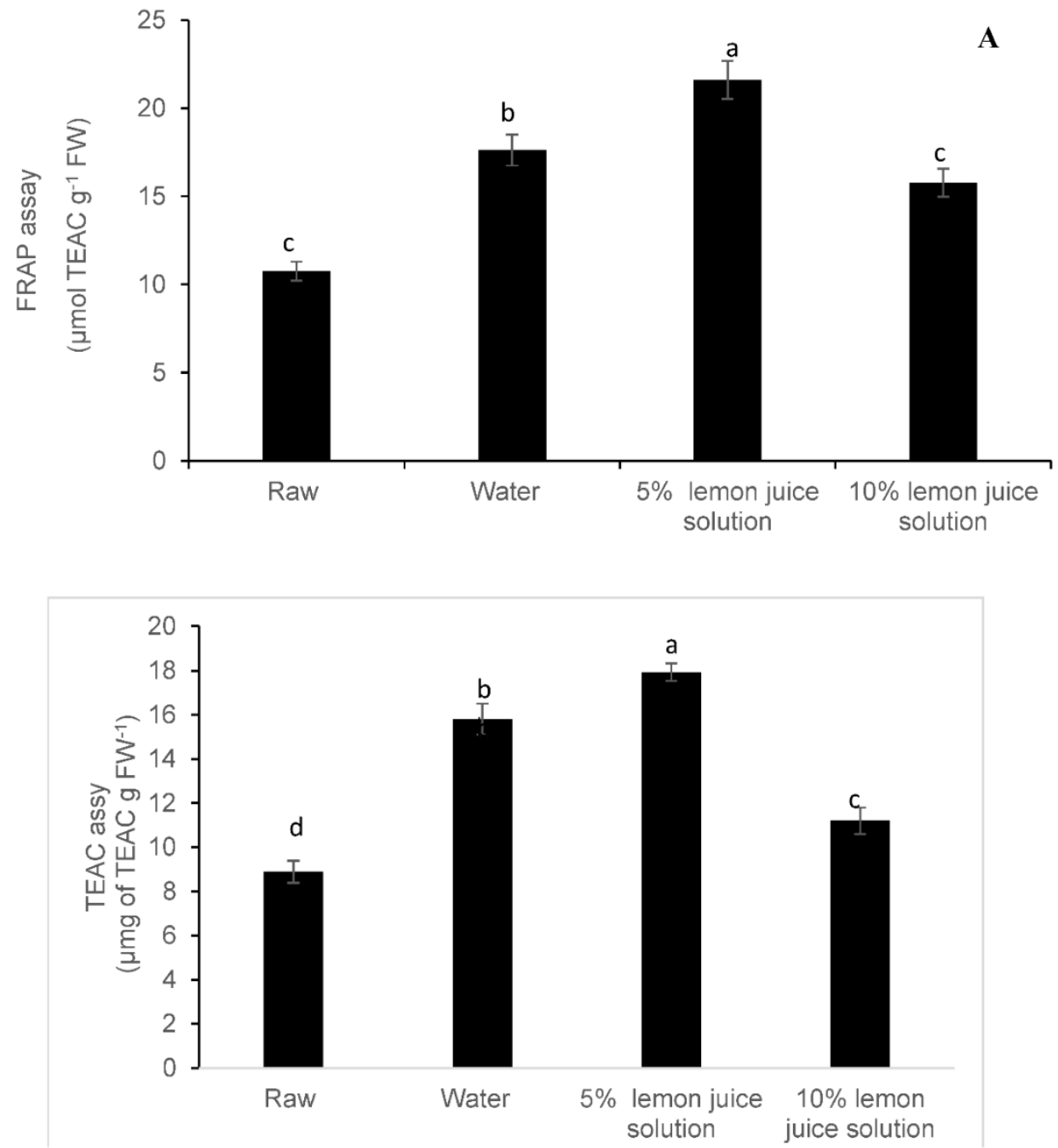

B

Figure 6. Effect of different types of moist cooking blanching treatments using a hot water bath at $95{ }^{\circ} \mathrm{C}$ on antioxidant capacity: (A) ferric reducing-antioxidant power assay (FRAP) and (B) Trolox equivalent antioxidant capacity (TEAC) assay in Chinese cabbage leaves. Bars with the same alphabetic letter for a specific phenolic compound are not significantly different at $p<0.05$.

The concentration of glucosinolate sinigrin in freshly harvested Chinese cabbage (Brassica rapa L. subsp. chinensis) was almost $1.5 \mu \mathrm{g} \mathrm{g}^{-1}$ (Figure 7). The concentration significantly increased with the concentration of lemon juice (lower $\mathrm{pH}$ ) at $95{ }^{\circ} \mathrm{C}$ (Figure 7). Furthermore, 1-Methoxy glucobrassicin was detected at lower concentrations than $0.1 \mu \mathrm{g} \mathrm{g}^{-1}$. However, 1 -methoxy glucobrassicin increased up to 0.3 and $0.6 \mu \mathrm{g} \mathrm{g}^{-1}$ with increasing concentrations of lemon juice at $5 \%$ and $10 \%$, respectively (data not presented). The total ion chromatogram in the ESI negative mode for glucosinolate sinigrin related to different blanching medium during hot water bath is given in Figure S2. 


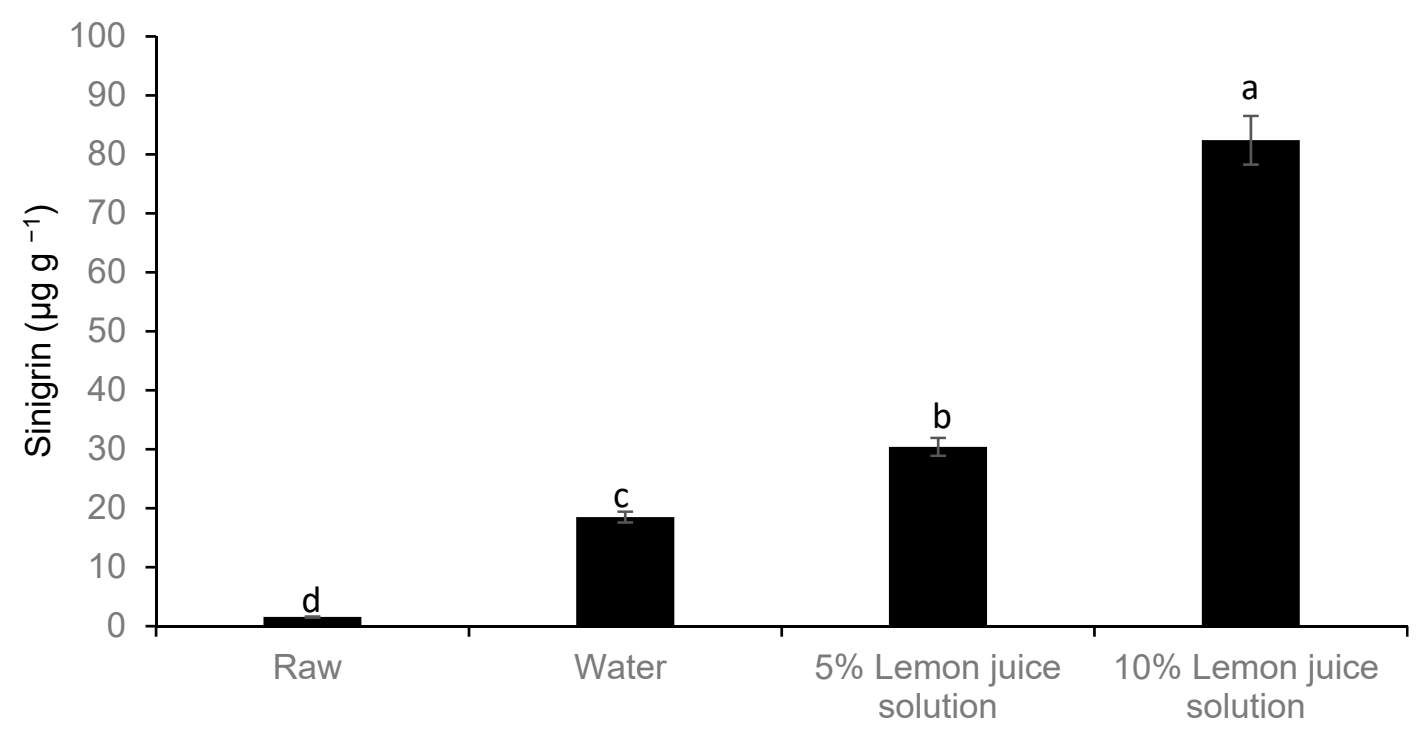

Figure 7. Effect of different types of moist cooking blanching treatments using a hot water bath at $95^{\circ} \mathrm{C}$ on the concentration of predominant glucosinolate sinigrin. Bars with the same alphabetic letter are not significantly different at $p<0.05$.

\section{Discussion}

The primary parameter that determines the consumer purchasing power of a food product is colour [17]. Consumers like to purchase leafy vegetables that are fresh and green in colour. Green peppers blanched in lemon juice or vinegar lost their green colour and chlorophyll content due to the acidity of the treatments. However, it is important to note here that the increase in concentration of lemon juice in water played a major role in determining the colour change [18]. Also, the lower $\mathrm{pH}$ environment of the $20 \%$ lemon juice blanching medium would have facilitated the conversion of chlorophyll to pheophytins and was responsible for the loss of green colour as reported by Gunawan et al. [19]. The pheophytin and pheophorbide are produced because of the replacement of the magnesium ion in the porphyrin ring by hydrogen ions in the presence of a low $\mathrm{pH}$ medium [20]. Thus, the increase in colour difference was due to the change of the green colour to olive brown due to the formation of pheophytin and pheophorbide [20]. However, pheophytin was not quantified in this study. Furthermore, blanching inactivates the chlorophyllase enzyme responsible for the rapid degradation of the green colour [21]. Blanching in a hot water bath in $5 \%$ lemon juice acidic solution had improved the retention of total chlorophyll content mainly due to the improved extractability of the chlorophyll because of the matrix changes. The higher temperature, $95^{\circ} \mathrm{C}$, during hot water blanching could result in a greater rupturing of cell structure, which would have led to better solvent access and extraction [22]. A similar increase in chlorophyll content during blanching was reported in coriander leaves [23].

Thermal blanching treatments were shown to inactivate the polyphenol oxidase activity that uses the polyphenols as substrates for the browning reaction [24]. Also, the lower $\mathrm{pH}$ was shown to improve the extraction yield of phenolics [25], which could be responsible for the observed increase in total phenols compared to that of the raw Chinese cabbage leaves in this study (Figure 3). However, some researchers have shown a decrease in total phenolic compounds due to thermal degradation and leaching into the water [26]. The degree of the degradation of polyphenols depends on the processing time, heat and the portion size of the vegetables [27]. Some researchers have shown that warm treatments did not affect the level of polyphenols or kaempferol in onions, green beans and peas [28]. Furthermore, thermal treatments can inactivate the oxidative enzymes that are responsible for the oxidation of antioxidants and as a result can increase the antioxidant activity [29]. Also, according to the literature, thermal treatments have shown a significant increase in antioxidant activity in pepper, green beans, spinach, broccoli [30], tomato [31], broccoli cauliflower [32] possibly due to the increased 
discharge of antioxidant constituents from the matrix or the formation of redox-active secondary plant metabolites or breakdown products [33]. Furthermore, the total phenolic content and the antioxidant activity in sweet potato leaf polyphenols were higher in a neutral and weak acid $\mathrm{pH}$ solvent system and in neutral and weak acid solvent systems [34]. There was an increase in quinic acid in mild acidic condition with increasing temperature [34]. In this study, an increase in quinic acid in mild acidic conditions with increasing temperatures could have induced the significant changes of the total phenols [34]. Therefore, using a high acid concentration and thermal treatments must be avoided during the moist cooking of Chinese cabbage. Also, the strong acidic conditions and temperatures were reported to affect the quinic acid derivatives (esters) especially in chlorogenic acids where the reduce the number caffeoyl groups demonstrated a decreased antioxidant activity of molecule [35]. Quinic acid can be used as a flavour enhancer due to its characteristic astringent taste. Kaempferol glycosides were predominantly detected in Brassica cultivars. In Ethiopian kale (B. carinta), which is a popular indigenous vegetable in East Africa, belongs to the same Brassicaceae family and contains higher levels of coumaroyl-glucoside and a higher number of kaemperol and isorhamnetin diglycosides [36]. However, in Chinese cabbage (Brassica rapa L. subsp. chinensis), isorhamnetin diglycosides were not detected.

Cauliflower blanched in water at $100{ }^{\circ} \mathrm{C}$ for $3 \mathrm{~min}$ was reported to reduce the total kaempferol content [37]. An increase in the concentration of the lemon juice (acidic conditions) at $95{ }^{\circ} \mathrm{C}$ affected the changes in the concentrations of the different kaempferol glycosides (kaempferol-dihexoside, kaempferol hexoside) and some are glycosylated with sophorotrioses-the kaempferol $O$-sophoroside- $O$-hexoside and myrectin- $O$-arabinoside in this study. A catalytic reverse shift reaction of kaempferol and myrectin glycosides or the release of bound phenolics into free phenolic derivatives [37] could possibly have taken place for the increase during blanching in $5 \%$ lemon solution at $95{ }^{\circ} \mathrm{C}$. However, further investigations are needed to prove this hypothesis. Furthermore, the thermostability of flavonoids was reported to be dependent on their glycosylation and acylation status and an increase in non-acylated quercetin compounds was shown during thermal processing especially baking [38]. Also, the disappearance of protocatechuoyl hexose blanching treatment (heat) could possibly have been due to the ruptured phenol-sugar bond and resulted in the formation of the simple phenolic structure of the aglycone [38].

Similarly, an increase in quercetin-4'-O-monoglucoside and quercetin-3'-O-diglucoside in onions were shown to increase at higher temperatures, at $120^{\circ} \mathrm{C}$, in different onion cultivars-Colossal, Sunpower, Chairman, and 110,455 [39]. A low acidic medium during food processing that was reported to increase the flavone glycosides and the conversion of apiin to apigenin 7-O-glucoside in celery juice was reported at $\mathrm{pH} 5$ [40]. It is important that the moist cooking blanching at $\mathrm{pH} 5$ could facilitate the increase in kaempferol glycosides and potentially modulate its intestinal absorption and metabolism [40]. However, further investigations are needed to confirm its bioavailability for intestinal absorption. Kaempferol has shown numerous health benefits, mainly with anticarcinogenic, antiinflammatory, anti-obesity, and antiviral properties and its activities [38].

The total glucosinolate content in different cauliflower varieties such as cv. 'Aviso', 'Dania' (white varieties), 'Grafitti' (purple), 'Emeraude' (green) and 'Celio' (green pyramidal) were lost by $55 \%$ and $42 \%$ during blanching and boiling, respectively [41]. Similarly, in red cabbage, Brassica oleracea L. ssp. capitataf. rubra cv. 'Autoro', the glucosinolate content was reduced by $64 \%, 38 \%$ and $19 \%$ during blanching, boiling and steaming respectively [42]. However, steaming showed the least effect on the antioxidant constituents in cauliflower varieties [41]. Probably during blanching or boiling at higher concentrations, functional compounds are leached into the processing water [41]. Chinese cabbage (Brassica rapa L. subsp. chinensis) contains sinigrin as the predominant glucosinolate in this study. On the one hand, the blanching treatment was reported to reduce the total glucosinolate content of cabbage and $53 \%$ loss of sinigrin was reported during cooking, mainly due to leaching effects [43]. The blanching treatment was reported to reduce the total glucosinolate content of cabbage and a 53\% loss of sinigrin was reported during cooking, mainly due to leaching effects [43]. On the other hand, the thermal process 
was suggested to reduce the formation of isothiocyanate, which possesses many health benefits such as antimicrobial, anti-inflammatory, antithrombotic and chemopreventive effects [44]. Ethopian kale (B. carinata) contains higher concentrations of glucosinolate aliphatic alkenyl glucosinolate 2-propeny, which has a chemo preventive property [43]. Therefore, the $\mathrm{pH}$ and temperatures during the different food preparation methods are important to maintain the biologically active isothiocyanate. In addition, the highest activity of myrosinase was reported in broccoli at $\mathrm{pH}$ 6.5-7.6 and in Brussels sprouts at $\mathrm{pH}$ 8 [45]. At the same time, the optimum temperature for myrosinase activity in broccoli and Brussels sprouts was reported to be 30 and $50{ }^{\circ} \mathrm{C}$, respectively $[45,46]$. However, moist cooking blanching at $95^{\circ} \mathrm{C}$ in $5 \%$ lemon juice could have inactivated the thermolabile endogenous myrosinase and the lower $\mathrm{pH}$ of the lemon solution could have prevented further hydrolysis during cell lysis in the process. However, further investigations are needed to elucidate the mechanism. Similarly, short blanching for 5 min in boiling water and fermentation with probiotic strain Lactobacillus paracasei LMG P22043 at a final $\mathrm{pH}$ of 4.12 reduced the loss of glucosinolates [43].

\section{Conclusions}

It is evident from this study that the moist cooking blanching affected the colour, chlorophyll content, phenolic and glucosinolate components and antioxidant properties. Moist cooking blanching using $20 \%$ lemon water significantly affected the colour, chlorophyll content, phenolic component and sinigrin glucosinolates and the antioxidant properties. However, moist cooking blanching using $5 \%$ lemon water significantly retained the colour and chlorophyll content and increased the concentration of kaempferol glycosides, gluconic acid, sinigrin glucoside and antioxidant activity. Further investigations are needed to explain the changes in the concentrations of kaempferol derivatives during moist cooking blanching using $5 \%$ lemon water and to investigate the biological effects.

Supplementary Materials: The following are available online at http://www.mdpi.com/2304-8158/8/9/399/s1. Figure S1: Comparison of UPLC-Q-TOF/MS chromatogram illustrating the changes in phenolic compounds in (A) Raw Chinese cabbage leaves, blanching treatment using hot water bath at $95^{\circ} \mathrm{C}$ using (B) $5 \%$ lemon juice as (C) using water as blanching (D) $10 \%$ lemon juice as blanching medium. The chromatograms of three replicates of each treatment (raw sample, 5\% lemon juice, water, $10 \%$ lemon juice) were included. The relative peak intensity is normalized, and peaks are expressed as the percentage highest peak intensity; Figure S2: Comparison of UPLC-Q-TOF/MS chromatogram illustrating the changes in sinigrin (aliphatic glucosinolate) in (A) Raw Chinese cabbage leaves, blanching treatment using hot water bath at $95^{\circ} \mathrm{C}$ using (B) $5 \%$ lemon juice as (C) using water as blanching (D) 10\% lemon juice as blanching medium. The relative peak intensity is normalized, and peaks are expressed as the percentage highest peak intensity.

Author Contributions: M.G.M., doctoral student, performed research work and wrote the first draft; F.R., supervisor of the postgraduate programme, edited the manuscript; C.G., methodology; D.S., Conceptualization, funding and responsible for the project.

Funding: The financial support from the Department of Science and Technology, Government of South Africa and the National Research Foundation (Grant number 98352) for Phytochemical Food Network to Improve Nutritional Quality for Consumers is greatly acknowledged.

Acknowledgments: The technical support provided by Peter P. Tinyani (Phytochemical Food Network research group, Department of Crop Sciences, Tshwane University of Technology is greatly acknowledged. Authors also sincerely thank Malcom Taylor form the Central Analytical Facilities (CAF) Stellenbosch University, South African for the assistance in UPLC-Q-TOF/MS analysis.

Conflicts of Interest: No conflict of interest between the authors.

\section{References}

1. Van Averbeke, W.; Netshithuthuni, C. Effect of Irrigation Scheduling on Leaf Yield of Nonheading Chinese Cabbage (Brassica rapa L. subsp. chinensis). South Afr. J. Plant Soil 2010, 27, 322-327. [CrossRef]

2. Mampholo, B.M.; Sivakumar, D.; Beukes, M.; van Rensburg, J.W. Effect of modified atmosphere packaging on the quality and bioactive compounds of Chinese cabbage (Brasicca rapa L. ssp. chinensis). J. Sci. Food Agric. 2013, 93, 2008-2015. [CrossRef] [PubMed] 
3. Yang, J.; Zhu, Z.; Wang, Z.; Biao Zhu, S. Effects of storage temperature on the contents of carotenoids and glucosinolates in pakchoi (Brassica rapa L. ssp. var. Communis). J. Food Biochem. 2010, 34, 1186-1204. [CrossRef]

4. Sturm, C.; Wagner, A.E. Brassica-derived plant bioactives as modulators of chemopreventive and inflammatory signaling pathways. Int. J. Mol. Sci. 2017, 18, 1890. [CrossRef] [PubMed]

5. Lippmann, D.; Lehmann, C.; Florian, S.; Barknowitz, G.; Haack, M.; Mewis, I.; Kipp, A.P. Glucosinolates from pak choi and broccoli induce enzymes and inhibit inflammation and colon cancer differently. Food Funct. 2014, 5, 1073-1081. [CrossRef] [PubMed]

6. Herz, C.; Marton, M.R.; Tran, H.T.T.; Grundemann, C.; Schell, J.; Lamy, E. Benzyl isothiocyanate but not benzyl nitrile from Brassicales plants dually blocks the COX and LOX pathway in primary human immune cells. J. Funct. Foods. 2016, 23, 135-143. [CrossRef]

7. Guzmán-Pérez, V.; Bumke-Vogt, C.; Schreiner, M.; Mewis, I.; Borchert, A.; Pfeiffer, A.F.H. Benzylglucosinolate derived isothiocyanate from Tropaeolum majus reduces gluconeogenic gene and protein expression in human cells. PLoS ONE 2016, 11, e0162397. [CrossRef] [PubMed]

8. Onyeoziri, I.O.; Kinnear, M.; de Kock, H.L. Relating sensory profiles of canned amaranth (Amaranthus. cruentus), cleome (Cleome gynandra), cowpea (Vigna. unguiculata) and Swiss chard (Beta vulgaris) leaves to consumer acceptance. J. Sci. Food Agric. 2018, 98, 2231-2242. [CrossRef]

9. Schlotz, N.; Odongo, G.; Herz, C.; Waßmer, H.; Kühn, C.; Hanschen, F.S.; Neugart, S.; Binder, N.; Ngwene, B.; Schreiner, M.; et al. Are Raw Brassica Vegetables Healthier Than Cooked Ones? A Randomized, Controlled Crossover Intervention Trial on the Health-Promoting Potential of Ethiopian Kale. Nutrients 2018, 10, 1622. [CrossRef]

10. Hanschen, F.S.; Lamy, E.; Schreiner, M.; Rohn, S. Reactivity and stability of glucosinolates and their breakdown products in foods. Angew. Chem. Int. Ed. 2014, 53, 11430-11450. [CrossRef]

11. Nugrahedi, P.Y.; Verkerk, R.; Widianarko, B.; Dekker, M. A mechanistic perspective on process-induced changes in glucosinolate content in Brassica vegetables: A review. Crit. Rev. Food Sci. Nutr. 2015, 55, 823-838. [CrossRef] [PubMed]

12. Eyarkai Nambi, V.; Gupta, R.K.; Kumar, S.; Sharma, P.C. Degradation kinetics of bioactive components, antioxidant activity, colour and textural properties of selected vegetables during blanching. J. Food Sci. Technol. 2016, 53, 3073-3082. [CrossRef] [PubMed]

13. Ndou, A.; Tinyani, P.P.; Slabbert, R.M.; Sultanbawa, Y.; Sivakuma, D. An integrated approach for harvesting Natal plum (Carissa macrocarpa) for quality and functional compounds related to maturity stage. Food Chem. 2019, 293, 499-510. [CrossRef] [PubMed]

14. Stander, M.; Van Wyk, B.E.; Taylor, M.J.C.; Long, H.S. Analysis of Phenolic Compounds in Rooibos Tea (Aspalathus linearis) with a Comparison of Flavonoid-Based Compounds in Natural Populations of Plants from Different Regions. J. Agric. Food Chem. 2017, 65, 10270-10281. [CrossRef] [PubMed]

15. Mpai, S.; du Preez, R.; Sultanbawa, Y.; Sivakumar, D. Phytochemicals and nutritional composition in accessions of Kei-apple (Dovyalis caffra): Southern African indigenous fruit. Food Chem. 2018. 253, 37-45. [CrossRef]

16. Egea, I.; Sánchez-Bel, P.; Romojaro, F.; Pretel, M.T. Six edible wild fruits as potential antioxidant additives or nutritional supplements. Plant Foods Hum. Nutr. 2010, 65, 121-129. [CrossRef] [PubMed]

17. Rawson, A.; Patras, A.; Tiwari, B.K.; Noci, F.; Koutchma, T.; Brunton, N. Effect of thermal and non-thermal processing technologies on the bioactive content of exotic fruits and their products: Review of recent advances. Food Res. Int. 2011, 44, 1875-1887. [CrossRef]

18. Al-Dabbas, M.; Saleh, M.; Hamad, H.; Hamadeh, W. Chlorophyll color retention in green pepper preserved in natural lemon juice. J. Food Process. Pres. 2016, 41, 1-6. [CrossRef]

19. Gunawan, M.I.; Barringer, S.A. Green color degradation of blanched broccoli (Brassica oleracea) due to acid and microbial growth. J. Food Process. Pres. 2000, 24, 253-263. [CrossRef]

20. Minguez-mosquera, M.I.; Garrido-Fernandez, J.; Gandul-Rojas, B. Pigment changes in olives during fermentation and brine storage. J. Agric. Food Chem. 1989, 37, 8-11. [CrossRef]

21. Koca, N.; Karadeniz, F.; Burdurlu, H.S. Effect of $\mathrm{pH}$ on chlorophyll degradation and color loss in blanched green peas. Food Chem. 2007, 100, 609-615. [CrossRef]

22. Youssef, K.M.; Mokhtar, S.M. Effect of Drying Methods on the Antioxidant Capacity, Color and Phytochemicals of Portulaca oleracea L. Leaves. Int. J. Food Sci. Nutr. 2014, 4, 4-6. [CrossRef] 
23. Ahmed, J.; Shivhare, U.S.; Singh, G. Drying characteristics and product quality of coriander leaves. Food Bioprod. Process. 2011, 79, 103-106. [CrossRef]

24. Devece, C.; Rodríguez-López, J.N.; Fenoll, L.G.; Tudela, J.; Catalá, J.M.; de los Reyes, E.; García-Cánovas, F. Enzyme inactivation analysis for industrial blanching applications: comparison of microwave, conventional, and combination heat treatments on mushroom polyphenoloxidase activity. J. Agric. Food Chem. 1999, 47, 4506-4511. [CrossRef] [PubMed]

25. Ruenroengklin, N.; Zhong, J.; Duan, X.; Yan, B.; Li, J.; Jiang, Y. Effects of various temperatures and pH values on the extraction yield of phenolics from litchi Fruit pericarp tissue and the antioxidant activity of the extracted anthocyanins. Int. J. Mol. Sci. 2008, 9, 1333-1341. [CrossRef] [PubMed]

26. Gonçalves, E.M.; Pinheiro, J.; Abreu, M.; Brandão, T.R.S.; Silva, C.L.M. Carrot (Daucus carota L.) peroxidase inactivation, phenolic content and physical changes kinetics due to blanching. J. Food Eng. 2010, 97, 574-581.

27. Sikora, E.; Cieslik, E.; Leszczynska, T.; Filipiak Florkiewicz, A.; Pisulewski, P. The antioxidant activity of selected cruciferous vegetables subjected to aqua thermal processing. Food Chem. 2008, 107, 55-59. [CrossRef]

28. Ewalda, C.; Fjelkner-Modig, S.; Johansson, K.; Sjöholm, I.; Åkesso, B. Effect of processing on major flavonoids in processed onions, green beans, and peas. Food Chem. 1999, 64, 231-235. [CrossRef]

29. Yamaguchi, T.; Mizobuchi, T.; Kajikawa, R.; Kawashima, H.; Miyabe, F.; Terao, J. Radical-scavenging activity of vegetables and the effect of cooking on their activity. Food Sci. Technol. Res. 2001, 7, 250-257. [CrossRef]

30. Turkmen, N.; Sari, F.; Velioglu, S. The effect of cooking methods on total phenolics and antioxidant activity of selected green vegetables. Food Chem. 2005, 93, 713-718. [CrossRef]

31. Gahler, S.; Otto, K.; Bohm, V. Alterations of vitamin C, total phenolics, and antioxidant capacity as affected by processing tomatoes to different products. J. Agric. Food Chem. 2003, 51, 7962-7968. [CrossRef] [PubMed]

32. Wachtel-Galor, S.; Wong, K.W.; Benzie, I.F.F. The effect of cooking on Brassica vegetables. Food Chem. 2008, 110, 706-710. [CrossRef]

33. Korus, A.; Lisiewska, Z. Effect of preliminary processing and method of preservation on the content of selected antioxidative compounds in kale (Brassica oleracea L. var. acephala) leaves. Food Chem. 2011, 129, 149-154. [CrossRef]

34. Sun, H.S.; Mu, T.H.; Xi, L.S. Effect of $\mathrm{pH}$, heat, and light treatments on the antioxidant activity of sweet potato leaf polyphenols. Int. J. Food Prop. 2017, 20, 318-332. [CrossRef]

35. Iwai, K.; Kishimoto, N.; Kakino, Y.; Mochida, K.; Fujita, T. In Vitro Antioxidative Effects and Tyrosinase Inhibitory Activities of Seven Hydroxycinnamoyl Derivatives in Green Coffee Beans. J. Agric. Food Chem. 2004, 52, 4893-4898. [CrossRef] [PubMed]

36. Neugart, S.; Baldermann, S.; Ngwene, B.; Wesonga, J.; Schrein, M. Indigenous leafy vegetables of Eastern Africa-A source of extraordinary secondary plant metabolites. Food Res. Int. 2017, 100, 411-422. [CrossRef] [PubMed]

37. Ahmed, F.A.; Ali, R.F.M. Bioactive compounds and antioxidant activity of fresh and processed white cauliflower. Biomed Res Int. 2013, 367819, 1-9. [CrossRef]

38. Juániz, I.; Ludwig, I.A.; Huarte, E.; Pereira-Caro, G.; Moreno-Rojas, J.M.; Cid, C.; De Peña, M.P. Influence of heat treatment on antioxidant capacity and (poly)phenolic compounds of selected vegetables. Food Chem. 2016, 197, 466-473.

39. Klopsch, R.; Baldermann, S.; Voss, A.; Rohn, S.; Schreiner, M.; Neugart, S. Bread enriched with legume microgreens and leaves - ontogenetic and baking-driven changes in the profile of secondary plant metabolites. Front. Chem. 2018, 6, 1-8. [CrossRef]

40. Hostetler, G.L.; Riedl, K.M.; Schwartz, S.J. Effects of food formulation and thermal processing on flavones in celery and chamomile. Food Chem. 2013, 141, 1406-1411. [CrossRef]

41. Volden, J.; Borge, G.I.A.; Hansen, M.; Wicklund, T.; Bengtsson, G.B. Processing (blanching, boiling, steaming) effects on the content of glucosinolates and antioxidant-related parameters in cauliflower (Brassica oleracea L. ssp. botrytis). LWT-Food Sci. Technol. 2009, 42, 63-73. [CrossRef]

42. Volden, J.; Borge, G.I.A.; Bengtsson, G.B.; Hansen, M.; Thygesen, I.E.; Wicklund, T. Effect of thermal treatment on glucosinolates and antioxidant-related parameters in red cabbage (Brassica oleracea L. ssp. capitata f. rubra). Food Chem. 2008, 109, 595-605. [CrossRef]

43. Sarvan, I.; Valerio, F.; Lonigr, O.; de Candia, S.; Verkerk, R.; Dekker, M.; Lavermicocca, P. Glucosinolate content of blanched cabbage (Brassica oleracea var. capitata) fermented by the probiotic strain Lactobacillus paracasei LMG-P22043. Food Res. Int. 2013, 54, 706-710. [CrossRef] 
44. Chen, X.; Hanschen, F.S.; Neugart, S.; Schreiner, M.; Vargas, S.A.; Gutschmann, B.; Baldermann, S. Boiling and steaming induced changes in secondary metabolites in three different cultivars of pak choi (Brassica rapa subsp. chinensis). J. Food Compos. Anal. 2019, 82, 103232. [CrossRef]

45. Hanschen1, F.S.; Klopsch1, R.; Oliviero, T.; Schreiner, M.; Verkerk, R.; Dekker, M. Optimizing isothiocyanate formation during enzymatic glucosinolate breakdown by adjusting $\mathrm{pH}$ value, temperature and dilution in Brassica vegetables and Arabidopsis thaliana. Sci. Rep. 2017, 7, 1-15. [CrossRef] [PubMed]

46. Ludikhuyze, L.; Rodrigo, L.; Hendrickx, M. The activity of myrosinase from broccoli (Brassica oleracea L. cv. italica): Influence of intrinsic and extrinsic factors. J. Food Prot. 2000, 63, 400-403. [CrossRef] [PubMed]

(C) 2019 by the authors. Licensee MDPI, Basel, Switzerland. This article is an open access article distributed under the terms and conditions of the Creative Commons Attribution (CC BY) license (http://creativecommons.org/licenses/by/4.0/). 